\title{
Pemberdayaan Masyarakat Kelurahan Suka Maju Melalui Pelatihan Pembuatan Sabun Kebutuhan Rumah Tangga
}

\author{
Munawarah $^{1}$, Keumala Hayati*2, Mas Intan Purba ${ }^{3}$, Wenny Anggeresia Ginting ${ }^{4}$ \\ 1,2,3,4 Program Studi Akuntansi, Fakultas Ekonomi, Universitas Prima Indonesia \\ *e-mail: keumalahayatihakim@gmail.com
}

\begin{abstract}
Soap is a necessity in the household that is continuously used, so the costs incurred are also quite large. The purpose of this washing soap training is to provide public knowledge especially housewives in Suka Maju Kelurahan in making soaps such as dishwashing soap, floor cleaning soap, detergent, softener and fragrances of clothes that are often used for daily needs, to reduce expenses routinely. This activity also encourages creativity and interest in trying to make them get an extra income. The team worked closely with the community empowerment agency Suka Maju Village,through the village funding program to create an independent, having soft skills community to be able to improve the economy. Activities that lasted for two days showed that public is enthusiastic and understands the workings of making products, as well as succeeding in making products well. T- test results also showed a sig value of 0.003 meaning that there were differences between before the activity took place and after the training.
\end{abstract}

Keywords: Liquid Soap, Community Empowerment, Suka Maju Village

\begin{abstract}
Abstrak
Sabun merupakan kebutuhan dalam rumah tangga yang terus menerus dikonsumsi, sehingga biaya yang dikeluarkan juga cukup besar. Tujuan dari pelaksanaan pelatihan sabun cuci ini adalah untuk memberikan pengetahuan masyarakat khususnya ibu rumah tangga di Kelurahan Suka Maju dalam membuat sabun seperti sabun cuci piring, sabun pembersih lantai, deterjen, pelembut serta pengharum pakaian yang kerap digunakan untuk kebutuhan sehari-hari, guna menekan pengeluaran rutin. Kegiatan ini juga mendorong kreativitas serta minat berusaha masyarakat agar dapat mendapat tambahan penghasilan. Tim bekerja sama dengan lembaga pemberdayaan masyarakat Kelurahan Suka Maju, melalui program dana kelurahan untuk mewujudkan masyarakat mandiri, berdaya guna, dan memiliki soft skill agar dapat meningkatkan ekonomi. Kegiatan yang berlangsung selama dua hari menunjukkan hasil maksimal. Masyarakat antusias dan memahami cara kerja pembuatan produk, sekaligus berhasil membuat produk dengan baik. Hasil uji beda juga menunjukkan nilai sig 0,003 artinya terdapat perbedaan antara sebelum kegiatan berlangsung, dan setelah kegiatan pelatihan
\end{abstract}

Kata kunci: Sabun Cair, Pemberdayaan Masyarakat, Kelurahan Suka Maju

\section{PENDAHULUAN}

Perkembangan zaman akan sejalan dengan semakin tingginya tingkat kebutuhan. Ibu rumah tangga dituntut untuk mampu menghasilkan disamping tugas utamanya sebagai istri dan ibu. Sulit rasanya jika hanya mengandalkan penghasilan dari suami mengingat nilai uang yang semakin tidak ada artinya. Mereka dituntut untuk mampu memanfaatkan barang kebutuhan rumah tangga yang setiap saat diperlukan. Hal ini berdampak pula pada pengeluaran rumah tangga yang rutin. Jika diperhatikan sebagian besar ibu rumah tangga tidak memiliki skill yang mumpuni sehingga menyebabkannya lebih memilih untuk tidak bekerja dan fokus untuk dirumah. Otomatis suami menjadi tumpuan utama. Ada kalanya penghasilan suami tidak mampu mencukupi kebutuhan rumah tangga yang sangat banyak tersebut.

Selain kebutuhan makan dan tempat tinggal, ada banyak kebutuhan lain yang tidak terlepas dalam rumah tangga, salah satunya adalah sabun. Sebagai bahan pembersih, sabun pada awalnya merupakan reaksi safonifikasi umumnya pada sabun padat, namun seiring perkembangan zaman jenis sabun tersebut mulai jarang dipergunakan karena kurang praktis. Sebagai gantinya digunakan turunan dari sabun dasar berupa surfaktan (bahan aktif permukaan). Surfaktan dipandang lebih praktis dalam aplikasi pembuatan pembersih termasuk sabun (Tanjung, 2018). Contohnya seperti cairan pembersih piring, deterjen untuk mencuci baju, cairan 
pembersih lantai dan segala kebutuhan lain yang sifatnya rutin. Hal ini tentu membuat pengeluaran cukup besar karena barang tersebut rutin dipakai dalam kegiatan sehari-hari. Sabun merupakan surfaktan yang digunakan dengan air untuk mencuci dan membersihkan. Surfaktan merupakan molekul yang memiliki gugus polar yang suka air (hidrofilik) dan gugus non polar yang suka minyak (lipofilik) sekaligus, sehingga dapat mempersatukan campuran yang terdiri dari minyak dan air (Sumanto, Adriantantri, Utomo, \& Widodo, 2016). Sabun cair lebih banyak digunakan masyarakat luas karena selain lebih higienis, dan mudah disimpan dalam wadah yang tertutup rapat (Apriyani, Diniah ; Saifullah, TN ; Indrayudha, 2013). Turunan dari senyawa ini juga dapat dihasilkan untuk memberikan efek harum dan lembut. Pelembut cucian merupakan Pelembut cucian merupakan bahan berupa cairan yang pada tahap saat akhir pada proses pencucian di tambahkan ke dalamnya, yang mempunyai tujuan melembutkan pakaian dan membuat pakaian berbau wangi. Pelembut pakaian disebut sebagai softener yang merupakan bahan berwujud cairan kental, sebagai pelengkap sewaktu mencuci baju yang sebelumnya sudah dicuci dengan detergent terlebih dahulu, juga berfungsi sebagai bahan pelembut dan pewangi pakaian (Kusumayanti, Heny;Paramita, Vita;Amalia, Rizka; Novela, Gina; Rhamvy, 2019) Dewasa ini dengan maraknya produk pelembut dan pewangi sekali bilas di masyarakat, dimana produk ini dapat menghilangkan busa deterjent dari pakaian dengan sekali bilas, menghemat pemakaian air (Laksono, Endang; SY, Isana; Marfuatun;Yuanita, 2018).

Pada dasarnya kebutuhan masyarakat terdiri dari kebutuhan primer, sekunder, dan tersier. Selain kebutuhan pokok untuk makan dan minum, keberadaan sabun sebagai kebutuhan utama yang menopang aktivitas sehari-hari juga dapat dianggap sebagai kebutuhan primer. Untuk mewujudkan standar kebersihan yang baik, masyarakat menggunakan sabun untuk membersikan peralatan makan, mencuci baju, membersihkan lantai, mencuci tangan, dan sebagainya. Tingginya pemakaian sabun setiap harinya, menyebabkan kebutuhan pengadaan sabun juga membutuhkan biaya yang tidak sedikit. Contohnya saja, harga sabun cuci piring dengan merk terkenal harganya kurang lebih Rp 15.000 per $800 \mathrm{ml}$ dengan pemakaian hanya maksimum 2 minggu. Untuk kebutuhan 1 bulan saja dibutuhkan Rp 30.000. Belum lagi jika masyarakat tersebut ada yang membuka usaha berjualan makanan, kebutuhan tersebut akan semakin meningkat. Begitu pula dengan kebutuhan lainnya. Deterjen 900 gr harganya Rp 16.000 untuk pemakaian 1 bulan, sementara deterjen cair Rp 5.000 per sachet, untuk kebutuhan satu bulan kurang lebih $\mathrm{Rp}$ 115.000. Softener per sachet Rp 4.800,- untuk pemakaian 1 bulan saja Rp 110.000. Jika ditotalkan kebutuhan untuk sebulan mencapai kurang lebih Rp 300.000 an. Jumlah ini tentu hampir menyerap sebagain pengeluaran rumah tangga, yang wajib dipenuhi.

Sesuai dengan program kerja dan arahan dari Walikota, Keluarahan Suka Maju selalu mempersiapkan program pemberdayaan masyarakat untuk warganya dengan target utama menciptakan masyarakat yang mandiri dan mampu meningkatkan ekonomi. Dengan jumlah penduduk kurang lebih 15.000 jiwa, wilayah ini sangat berpotensi untuk dijadikan wilayah pelatihan. Mengingat masih banyak jumlah masyarakat, khususnya ibu-ibu di Kelurahan tersebut yang kurang produktif dan tidak memiliki keterampilan khusus. Mengentaskan kemiskinan merupakan salah satu agenda penting dalam program pembangunan daerah. Mulai yang bersifat yang tidak langsung seperti latihan dan lokakarya hingga yang bersentuhan langsung dengan masyarakat seperti dana bergulir bagi koperasi, usaha kecil dan menengah, program pemberdayaan desa dengan cara menempatkan sejumlah dana di tingkat desa/kelurahan hingga bantuan pengadaan peralatan teknologi tepat guna bagi usaha kecil (Aprijon, 2013). Salah satu program pemberdayaan masyarakat tersebut adalah dengan melaksanakan pelatihan pembuatan sabun untuk kebutuhan rumah tangga. Pelatihan ini dipilih karena dinilai lebih mudah dan efisien, serta tidak membutuhkan modal yang besar. Peserta dapat langsung menggunakan produk yang telah dibuat tersebut untuk kebutuhannya sehari-hari, sekaligus menumbuhkan minat berwirausaha sehingga dapat meningkatkan perekonomian. Program pemberdayaan masyarakat baiknya wanita dibekali keterampilan untuk mengolah sendiri bahan kebutuhan rumah tangga tersebut sehingga meminimalisir pengeluaran, dan dapat mengalokasi dana untuk membeli sabun tersebut untuk kebutuhan lainnya atau ditabung. Dengan biaya yang minim, hasil yang diperoleh sangat banyak, dan dapat dimanfaatkan dalam waktu berbulan bulan. Kegiatan ini juga bertujuan 
untuk menumbuhkan semangat berwirausaha dengan adanya peluang usaha baru dari kemampuan dan keterampilan masyarakat yang meningkat. Program ini memiliki potensi keberlanjutan dan pengembangan yang cukup besar karena impelementasinya yang mudah dan aplikatif serta bisa menguntungkan kedua belah pihak (Warman, Mardian, Suryani, Fista, \& Irwan, 2020)

\section{METODE}

Dalam menyelesaikan permasalahan, dilakukan metode partisipasi aktif atau disebut juga metode Participatory Action Research (PAR). Metode ini bertujuan untuk membangun kesadaran masyarakat sekaligus memberdayakan masyarakat kelas menengah ke bawah melalui pemberian penyuluhan dengan materi yang telah ditentukan (Amalia et al., 2018), sekaligus pelatihan dalam membuat produk. Tim Pelaksana dan Kepala Lingkungan melakukan survey dengan memprioritaskan masyarakat yang dapat mengikuti pelatihan adalah dengan ekonomi ke bawah. Berdasarkan data dan hasil survey terpilih dua perwakilan dari masing-masing lingkungan yang ada di Wilayah Kelurahan Suka Maju. Total semua peserta sebanyak 26 orang perwakilan masyarakat dari Lingkungan I sampai Lingkungan XI dan 4 orang lagi dari Ibu-Ibu PKK yang ada di Kelurahan Suka Maju.

Kegiatan Pemberdayaan masyarakat sebagai program kerja Kelurahan Suka Maju dilaksanakan pada tanggal 16 sampai 17 Desember 2019. Agenda kegiatan ini melibatkan narasumber sekaligus instruktur dari dosen-dosen fakultas ekonomi Universitas Prima Indonesia sebanyak orang yang akan memberikan pendampingan pelatihan. Lokasi pelatihan dilaksanakan di Aula Kantor Lurah Suka Maju yaitu di Jalan STM No.40 Medan. Khalayak sasaran dari kegiatan ini adalah masyarakat khususnya ibu-ibu di Kelurahan Suka Maju dengan latar belakang usia produktif dan mayoritas hanya sebagai ibu rumah tangga.

\section{HASIL DAN PEMBAHASAN}

Selama kegiatan berlangsung, dapat diketahui masyarakat sangat antusias dalam mempraktekkan pengolahan sabun untuk kebutuhan rumah tangga tersebut. Masyarakat juga diberikan edukasi dan stimulus agar giat berwirausaha dari keterampilan yang dimiliki dari tim dosen ekonomi yang turut serta mendampingi peserta selama kegiatan.

Pada pertemuan pertama, pertama sekali dibuka dengan sambutan serta pengarahan dari Lurah berikut dengan Ketua Lembaga Pemberdayaan Masyarakat (LPM) Kelurahan Suka Maju. Berikutnya tim pelaksana, memberikan pemaparan materi singkat mengenai pengolahan sabun sekaligus meliterasi peserta dari sisi keuangan dengan menganalisis Usaha, Harga pokok produksi yang digunakan untuk memproduksi sabun cair, hingga perbandingan dengan harga jual. Sabun adalah surfaktan yang digunakan dengan air untuk mencuci dan membersihkan (Pasir \& Hakim, 2014). Masyarakat modern sekarang lebih memilih menggunakan sabun berbahan cair dengan alas an lebih praktis dan bisa dibawa kemana saja baik ukuran besar maupun kecil (Kusumayanti et al., 2018). Sehingga diperlukan campuran bahan-bahan kimia untuk membuatnya yang dapat dibeli pada Toko Juta Kimia yang berada di Jl Bintang Medan.

Bahan-bahan yang digunakan untuk pembuatan Sabun baik sabun cuci piring, deterjen cair, dan sabun pembersih lantai pada dasarnya hampir sama, yaitu Texapon, Sodium Sulfat, $\mathrm{Na}$ $\mathrm{Cl}$, Asam Sitrat, Ambitol, Parfum dan pewarna. Yang membedakan hanya pada kadar asam sitrat yang digunakan lebih banyak pada sabun pencuci piring, begitu pula parfum dan pewarna juga disesuaikan dengan kebutuhan sabun yang akan dibuat. Teknik pembuatan ketiga produk tersebut juga kurang lebih sama. Prinsipnya menggunakan 10, dan 5 liter air, dimana 5 liter pertama larutkan garam hingga merata, dan 10 liternya merupakan campuran bahan lainnya seperti texapon, sodium sulfat, asam sitrat, dan ambitol, menyusul bahan-bahan tambahan lainnya. Sedangkan untuk pembuatan cairan pelembut dan pengharum pakaian sekali bilas 
(softener) digunakan bahan Tetranyl (soft gel), Hydroxy Ethil Cellulose (HEC), bibit parfum, dan pewarna dengan cara mencampurkan tetranyl dengan air panas (1 liter), dan ditambahkan pula HEC lalu aduk hingga merata. Lalu menyusuk dengan bibit parfum dan pewarna yang dibutukan. Dan untuk pembuatan cairan pelicin setrika pakaian diperlukan bahan Etanol, Biang Parfum, Magnasoft, dan Sysil Liquid. Kesemua bahan tersebut dicampur dengan lebih dahulu memasukkan magnasoft dan sysil liquid, lalu menyusul bibit parfum dan aduk hingga merata, dan pada tahap akhir campurkan etanol.

Dari hasil pelatihan, diperoleh bahwa peserta dapat mengemas sabun cair seperti sabu pencuci piring, deterjen cair, dan sabum pembersih lantai ke dalam botol ukuran $500 \mathrm{ml}$, sehingga didapatkan 30 botol kemasan dari 15 liter cairan. Sedangkan untuk 1 paketan bahan softener menghasilkan 30 botol kemasan $100 \mathrm{ml}$, dan pelicin setrika pakaian diperoleh kurang lebih 25 botol kemasan $100 \mathrm{ml}$. Kondisi ini jelas sangat menguntungkan, dan menjadi peluang bisnis bagi masyarakat khususnya ibu-ibu rumah tangga di Kelurahan Suka Maju.

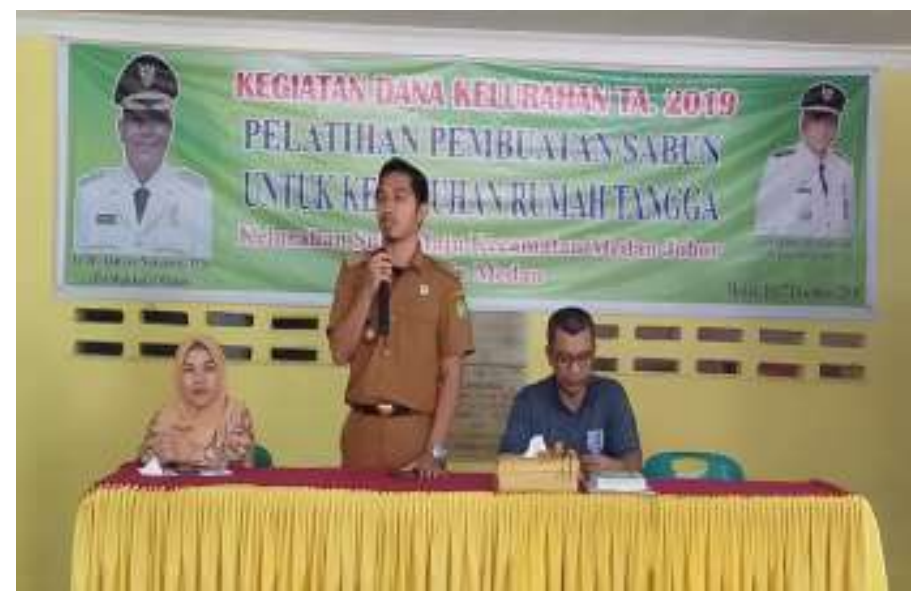

Gambar 1. Sosialisasi dari Lurah dan Kepala LPM Kelurahan Suka Maju

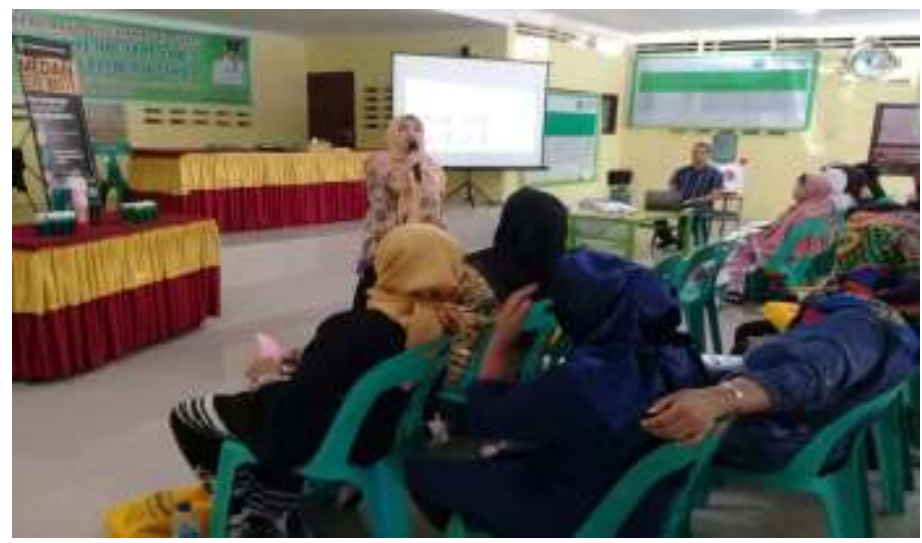

Gambar 2. Penyuluhan dan Literasi Keuangan 

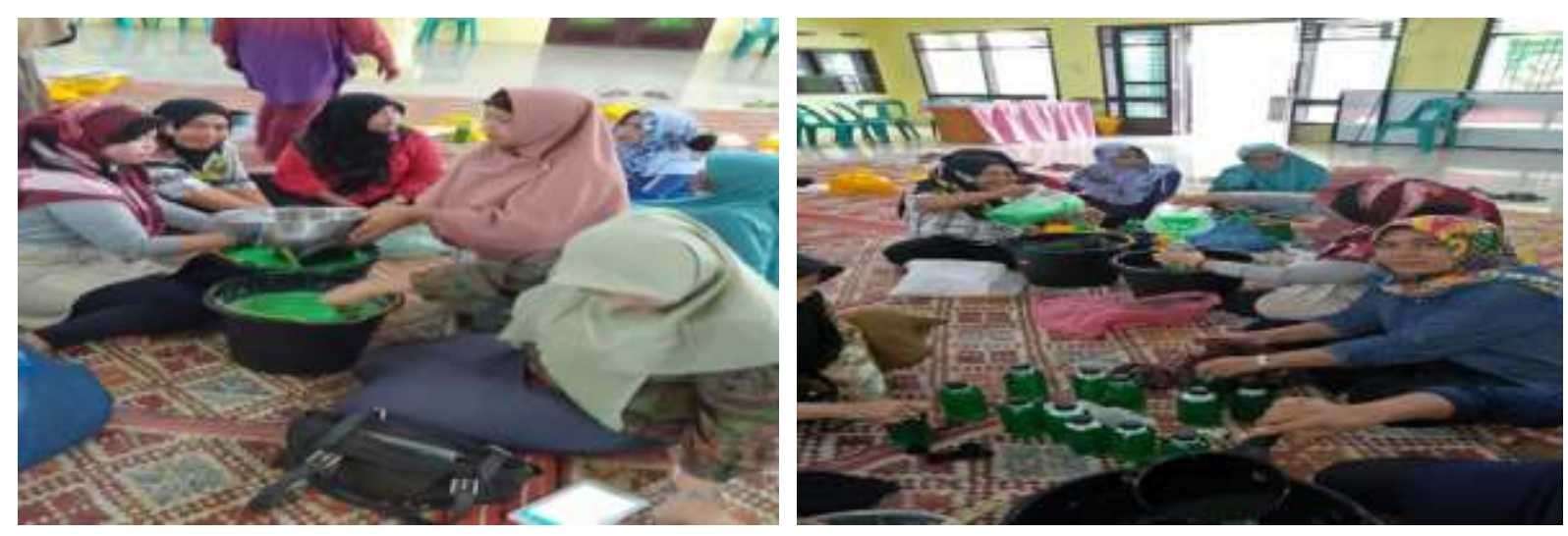

Gambar 3. Proses Pembuatan Sabun oleh Ibu-Ibu Kelurahan Suka Maju
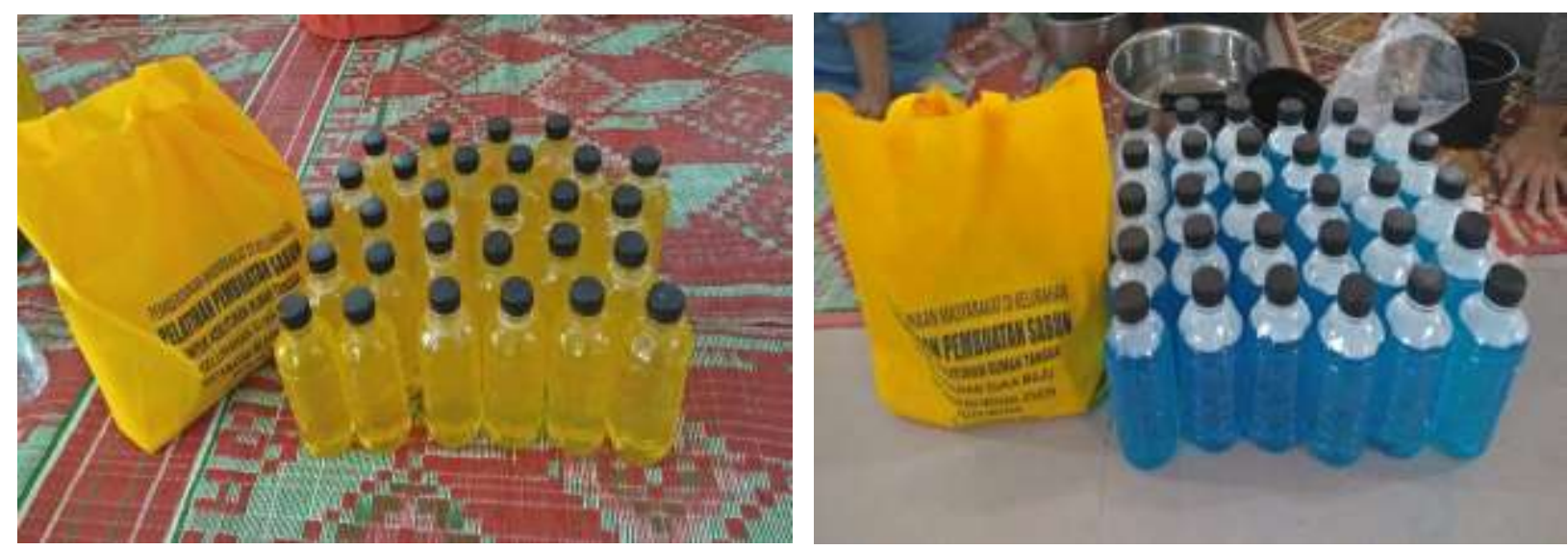

Gambar 4. Produk sabun yang telah selesai

Agar lebih terukur, tim juga memberikan kuisioner kepada para peserta untuk mengukur ada atau tidaknya perubahan setelah dilakukan pelatihan. Sebelum pelatihan, tim memberikan kusioner, dan setelah selesai pelatihan kuisioner kembali diberikan kepada peserta. Dari hasil test menunjukkan terdapat perbedaan dari sebelum pelaksanaan pelatihan dan setelah selesai pelatihan.

Tabel 1. Paired Sample Correlation

\begin{tabular}{cccc}
\hline & $\mathrm{N}$ & Correlation & Sig \\
\hline Pre Test \& Post Test & 26 & 0.281 & 0.164 \\
\hline
\end{tabular}

Tabel 2. Paired Sample Test (t-Test)

\begin{tabular}{cccc}
\hline & $\mathrm{t}$ & $\mathrm{df}$ & Sig. (2-tailed) \\
\hline PRE_TEST - POST_TEST & -3.357 & 25 & 0.003 \\
\hline
\end{tabular}

Hasil menunjukkan nilai signifikasi dari uji Paired (t-Test) sebesar 0,003 lebih kecil dari 0,05 artinya bahwa terdapat perbedaan yang signifikan antara hasil kegiatan, baik sebelum pelatihan (pretest) maupun sesudah pelatihan (posts-test) baik dari sisi pemakaian alat, pengetahuan,kemampuan, dan minat peserta pelatihan. 


\section{KESIMPULAN}

Berdasarkan hasil kegiatan pelatihan pembuatan sabun untuk keperluan rumah tangga, dapat dikatakan terjadi peningkatan kemampuan dan minat masyarakat yang cukup baik. Terlihat dari respon peserta dan hasil uji beda yang menunjukkan nilai sigifikan sebesar 0,003 . Jika dilihat dari nilai rata-rata test juga menunjukkan peningkatan motivasi dan keinginan untuk melanjutkannya menjadi usaha sendiri sebesar 9,69 yaitu dari 62,31 menjadi 72 . Hal ini membuktikan bahwa kegiatan pemberdayaan masyarakat melalui pelatihan pembuatan sabun cuci sangat bermanfaat bagi peserta terutama kaum ibu rumah tangga. Tentu saja kegiatan ini berdampak positif tidak hanya dari aspek sosial, namun juga mendorong aspek ekonomi sebagai roda utama perekonomian keluarga. Program pelatihan ini juga berpotensi untuk terus dikembangkan, mengingat mudahnya bahan serta proses pembuatannya. Pihak kelurahan Suka Maju tentu saja dapat menjadi jembatan untuk memudahkan warga masyarakat memperoleh dana tambahan dari pemerintah untuk mendorong pertumbuhan UMKM khususnya di wilayah tersebut.

\section{UCAPAN TERIMA KASIH}

Penulis mengucapkan terima kasih kepada Lembaga Pemberdayaan Masyarakat (LPM) Kelurahan Suka Maju Kecamatan Medan Johor yang telah melibatkan tim Dosen Fakultas Ekonomi Universitas Prima Indonesia dalam kegiatan pelatihan ini.

\section{DAFTAR PUSTAKA}

Amalia, R., Paramita, V., Kusumayanti, H., Wahyuningsih, W., Sembiring, M., \& Rani, D. E. (2018). Produksi Sabun Cuci Piring Sebagai Upaya Peningkatkan Efektivitas Dan Peluang Wirausaha. Metana, 14(1), 15. https://doi.org/10.14710/metana.v14i1.18657

Aprijon, A. (2013). Kewirausahaan dan Pandangan Islam. Menara Riau, 12(1), 1-11.

Apriyani, Diniah ; Saifullah, TN ; Indrayudha, P. (2013). Formulasi Sediaan Sabun Mandi Cair Minyak Atsiri Jeruk Nipis (Citrus Aurantifolia) Dengan Cocamid Dea Sebagai Surfaktan.

Kusumayanti, Heny;Paramita, Vita;Amalia, Rizka; Novela, Gina; Rhamvy, I. E. (2019). Pelatihan Ketrampilan Pembuatan Pelembut Dan Pewangi Pakaian Bagi Ibu - Ibu Pkk Di Desa Kangkung, Kecamatan Mranggen, Kabupaten Demak. Jurnal Pengabdian Vokasi, 01(02), 112-115.

Kusumayanti, H., Paramita, V., Wahyunimgsih, W., Amalia, R., Siregar, V. D., \& Pudiastuningtyas, N. (2018). Pelatihan Dan Praktek Pembuatan Sabun Cuci Tangan Cair Di Pkk Tembalang Pesona Asri. Gema Teknologi, 20(1), 24. https://doi.org/10.14710/gt.v20i1.21079

Laksono, Endang; SY, Isana; Marfuatun;Yuanita, D. (2018). Pelatihan Pembuatan Pelembut Cucian yang Ramah Lingkungan. Jurnal Pengabdian Masyarakat MIPA Dan Pendidikan MIPA, 2(1), 38-42.

Pasir, S., \& Hakim, M. S. (2014). Penyuluhan dan praktik pembuatan sabun cuci piring cair. Jurnal Inovasi Dan KewiraUsahaan, 3(3), 155-159. Retrieved from http://journal.uii.ac.id/index.php/ajie/article/download/7824/6837

Sumanto, Adriantantri, E., Utomo, A., \& Widodo, B. (2016). Pembuatan Sabun Cair di Tlogomas Malang. SENIATI, 157-161.

Tanjung, D. A. (2018). Pelatihan Pembuatan Sabun Cair Dan Shampoo Pencuci Mobil. Prodikmas Hasil Pengabdian Masyarakat, 2(1), 41-45.

Warman, J. S., Mardian, V., Suryani, L., Fista, F. R., \& Irwan, I. (2020). Program Pelatihan Penigkatan Kemampuan Bahasa Inggris Anak-Anak Panti Asuhan Melalui Pemberdayaan Mahasiswa. Dinamisia: Jurnal Pengabdian Kepada Masyarakat, 3(2), 280-285. https://doi.org/10.31849/dinamisia.v3i2.3304 